\title{
Effect of Temperatures on Polymerization Stress and Microleakage of Class V Composite Restorations
}

\author{
Pavinee Padipatvuthikul Didron $^{1 *}$, Wojciech Chrzanowski ${ }^{2}$, Ayman Ellakwa ${ }^{3,4}$ \\ ${ }^{1}$ Department of General Dentistry, Srinakharinwirot University, Bangkok, Thailand; ${ }^{2}$ Faculty of Pharmacy, University of Sydney, \\ Sydney, Australia; ${ }^{3}$ Faculty of Dentistry, The University of Sydney, Sydney, Australia; ${ }^{4}$ Faculty of Dentistry, Tanta University, Tanta, \\ Egypt. \\ Email: *pavinee.didron@gmail.com
}

Received July 22 ${ }^{\text {nd }}, 2013$; revised August 22 ${ }^{\text {nd }}, 2013$; accepted August $31^{\text {st }}, 2013$

Copyright (C 2013 Pavinee Padipatvuthikul Didron et al. This is an open access article distributed under the Creative Commons Attribution License, which permits unrestricted use, distribution, and reproduction in any medium, provided the original work is properly cited.

\begin{abstract}
The loss of interfacial integrity was identified as one of the major causes for replacement of resin composite restorations. Preheating procedure has been proven to enhance flowability and adaptation of resin composites and increase their degree of conversion. The purpose of this study was to investigate polymerization contraction stress produced in resin composites after preheating to $37^{\circ} \mathrm{C}$ and $60^{\circ} \mathrm{C}$, and measure microleakage of Class V restorations restored with preheated composites. Three resin composites (GC Kalore, Gradia Direct X, Filtek Supreme XT) at room temperature, $37^{\circ} \mathrm{C}$, and $60^{\circ} \mathrm{C}$ were investigated. Maximum contraction stress of the composites $(n=5)$ was evaluated in a modified lowcompliance device. Samples were light-cured for 40 seconds and the maximum force was recorded during 15 minutes. Calculations were done to adjust for the system's compliance and obtain linear shrinkage values of composites. Data were analyzed by Multivariated Analysis of Variance (MANOVA) and Tukey's test for multiple comparisons $(\alpha=$ 0.05). Seventy-two Class V cavities were prepared on the buccal surfaces of extracted premolars and divided into 9 groups. The teeth were restored with composites at 3 temperatures and were thermo-cycled between $5^{\circ} \mathrm{C}$ and $55^{\circ} \mathrm{C}$ with a one-minute dwell-time for 1000 cycles. The teeth were sealed with wax and nail vanish before placed in $0.5 \%$ toluidine blue dye for 24 hours. The teeth were embedded in self-curing resin and sectioned bucco-lingually with a slow-speed diamond saw, providing 3 sections per restoration. Microleakage was rated by two evaluators using a $0-4$ ordinal scale at the occlusal and cervical margins under light microscope. Microleakage data were analyzed with Kruskal-Wallis ANOVA and Mann-Whitney $\mathrm{U}$ test $(\alpha=0.05)$. Results indicate that preheating composites to $37^{\circ} \mathrm{C}$ and $60^{\circ} \mathrm{C}$ significantly increased polymerization contraction stress of composites $(p<0.05)$. A significantly greater amount of leakage was found at the cervical margins $(p<0.05)$. For all tested materials, preheating composites to $60^{\circ} \mathrm{C}$ resulted in significantly less microleakage at the cervical margin.
\end{abstract}

Keywords: Preheating; Dental Composite; Polymerization Shrinkage; Contraction Stress; Microleakage

\section{Introduction}

Improvements in resin composites' mechanical properties and their reduced polymerization shrinkage during the past decade encouraged clinicians to use resin composites more frequently for posterior restorations. Majorities of improvements aimed to improve microstructure of the material including monomer composition, size, shape, and distribution of inorganic filler particles and targeted mainly at increasing the filler load of resin composites. However, increasing the filler load resulted in higher viscosity and led to concerns about handling, packing, and adaptation of the material. Many attempts

\footnotetext{
"Corresponding author.
}

were made to enhance composite adaptation and decrease microleakage between composites and dental cavity, either by using the flowable composite as a base material, chemical and laser treatments of dentin or by preheating the composites to lower their viscosity.

The effect of lower viscosity in improvements of adaptation has been proven important. This is the primary basis for producing flowable resin composites in which the lower viscosity can be achieved by decreasing their filler contents and making changes in the matrix chemistry, which severely reduce their physical properties. Many polymers exhibit lower viscosity when they are heated because thermal vibrations force the composite monomer further apart and allow them to slide by each other more 
readily. This property leads to a concept of warming or preheating composite resins before photopolymerization, which will decrease the viscosity and increase flow of resin composites. In addition, composites cured at elevated temperatures have been proven to increase polymerization rate and have a higher degree of conversion [1-3], which could result in improved mechanical properties [4]. Also, it has been reported that increasing composite temperature up to $60^{\circ} \mathrm{C}$ might enhance the conversion degree on the top and in $2 \mathrm{~mm}$ of the bottom surfaces [2].

However, it has been reported that the increased degree of conversion associated with preheating would result in increased polymerization shrinkage [5]. One study has shown that temperature has a significant effect on polymerization shrinkage of microfilled composites. Preheating composites to relatively high temperatures $\left(54^{\circ} \mathrm{C}\right.$ or $68^{\circ} \mathrm{C}$ ) causes a significant increase in volumetric shrinkage, but preheating composites to a body temperature causes similar shrinkage to that at room temperature [6]. Advantages of preheating the resin are to make more durable, highly filled, highly viscous conventional composite resin, to reduce the viscosity, to provide flow values that are similar to those of less filled, flowable resin composites, without undermining the mechanical properties. However, more investigation is necessary to determine the side effects of preheating procedures such as an increase of the polymerization shrinkage which causes stress at the tooth/restoration interface and may cause microleakage of the restorations. The main objective of this study was to evaluate the effect of preheating on polymerization contraction stress of composites and the in vitro marginal microleakage. It was hypothesized that increasing the preheating temperature would increase the polymerization stress and increase the microleakage at resin composites/tooth interfaces.

\section{Materials and Methods}

\subsection{Polymerization Contraction Stress Measurement}

The materials used in this study are indicated in Table 1. Polymerization contraction stress was measured by a modified low-complicance device (Figure 1), consisting of 2 parts; the first part is a load cell, which a brass steel piston was attached. A brass steel piston (10 mm diameter; $30 \mathrm{~mm}$ length) was used as the bonding substrate for the composite. The piston had one surface abraded with \#180-grit sandpaper, coated with silane coupling agent prior to the application of a thin layer of unfilled resin (Adper ${ }^{\mathrm{TM}}$ Single Bond 2), and light-cured for 20 seconds (MiniLED, Satelec, France). A ringshape teflon mold was inserted at the end of the brass piston, created a cylindrical cavity (dimension $10 \mathrm{~mm}$ diameter $\times 1 \mathrm{~mm}$
Table 1. Materials used in the present study, their respective batch number and manufacturer.

\begin{tabular}{|c|c|c|}
\hline Material & Batch number & Manufacturer \\
\hline Filtek $^{\mathrm{TM}}$ Supreme XT & N151598 & $\begin{array}{l}\text { 3M ESPE, Dental Products, } \\
\text { St. Paul MN }\end{array}$ \\
\hline GC KALORETM & 910071 & $\begin{array}{l}\text { GC Corporation, } \\
\text { Tokyo, Japan }\end{array}$ \\
\hline Gradia $^{\mathrm{TM}}$ Direct X & 1201271 & $\begin{array}{l}\text { GC Corporation, Tokyo, } \\
\text { Japan }\end{array}$ \\
\hline Adper ${ }^{\mathrm{TM}}$ Single Bond 2 & N283944 & $\begin{array}{l}\text { 3M ESPE, Dental Products, } \\
\text { St. Paul MN }\end{array}$ \\
\hline Scotchbond ${ }^{\mathrm{TM}}$ Etchant & N287300 & $\begin{array}{l}\text { 3M ESPE, Dental Products, } \\
\text { St. Paul MN }\end{array}$ \\
\hline
\end{tabular}

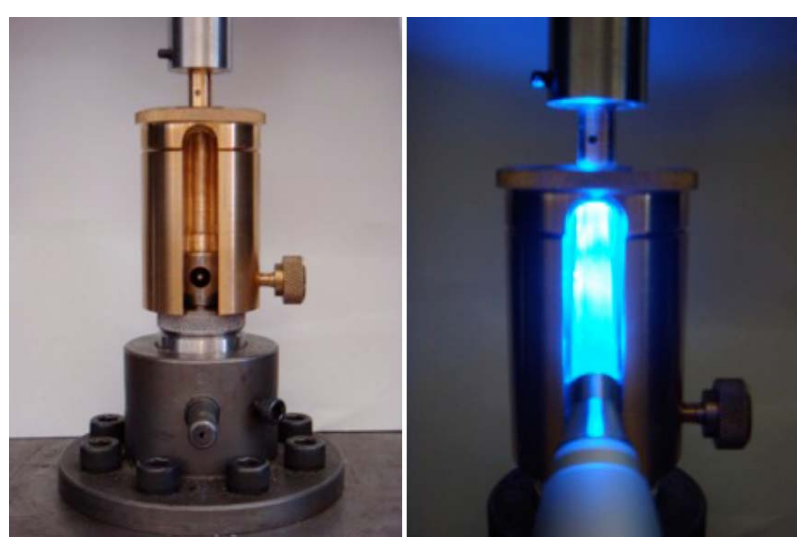

Figure 1. The test setup for the polymerization stress measurements.

thickness) for resin composite. Uncured resin composite was preheated and inserted in the mold, the mold was then removed. The brass piston with the composite was heated up to specific test temperature on a thermal controlled plate, a thermocouple was placed inside a hole in the brass piston at all time to measure the composite temperature.

The second part is a brass cylinder, holding a clear perspex disc (22 mm diameter; $1 \mathrm{~mm}$ thickness). The brass cylinder has a slot which allowed for the placement of the light guide of a curing unit in contact with the perspex disc. The top surface of perspex disc was abraded with \#180-grit sandpaper, cleaned, coated with a thin layer of unfilled resin (AdperTM Single Bond 2), and light-cured for $20 \mathrm{sec}$. When the desire temperature was reached, the brass piston was fixed to the load cell. The brass piston was driven down to just touched the perspex surface. The composite was photo-activated through the clear perspex disc. As the composite polymerized, contraction force was followed for $15 \mathrm{~min}$. The force values were converted to nominal stress by dividing them by the cross-sectional area of the specimen $\left(78.5 \mathrm{~mm}^{2}\right)$. Maximum contraction stress (Smax) was subjected to statistical analysis. 
Data were analyzed by Multivariated Analysis of Variance (MANOVA), entering resin composite and temperature as main factors, and Tukey's test for multiple comparisons $(\alpha=0.05)$.

\subsection{Microleakage Test}

\subsubsection{Tooth Selection}

Seventy-two extracted caries and restoration-free permanent human premolars were selected, remaining soft tissue removed, and stored in deionized water for a maximum duration of 4 weeks. The teeth were cleaned with slurry of pumice and water, rinsed thoroughly with tap water, and then examined macroscopically with magnification for defects in the enamel and dentin.

\subsubsection{Sample Preparation}

The teeth were randomly assigned into nine groups of eight. A Class V preparation was made in the buccal surface of each tooth. The occlusal margin of the cavities were in enamel and the gingival margins located $1.5 \mathrm{~mm}$ apical to the cemento-enamel junction. Preparations were made with a 329 carbide bur in a high-speed handpiece equipped with water spray. Cavity dimensions were standardized (5.0 mm in width, $3.0 \mathrm{~mm}$ in height, and $2 \mathrm{~mm}$ in depth). For all groups, enamel and dentin are etched with 35\% phosphoric acid gel (Scotchbond ${ }^{\mathrm{TM}}$ etchant, 3M Dental Products, MN, USA) for $20 \mathrm{~s}$ and $15 \mathrm{~s}$ respectively, rinsed for $20 \mathrm{~s}$, and air-dried to obtain chalkywhite appearance enamel and moist dentin. All cavities are treated with a resin-based adhesive system. The adhesive used in this study is Adper ${ }^{\mathrm{TM}}$ Single Bond 2 (3M ESPE, St. Paul, MN, USA). Wet-bonding technique is followed as recommended by the manufacturer, moist dentin was clinically evidenced by a uniform shiny surface on which water was not pooled. A fully saturated brush tip for each coat is used, applying two consecutive coats of Adper ${ }^{\mathrm{TM}}$ Single Bond 2 adhesive to prepared enamel and dentin. Later, the surface was dried gently for $5 \mathrm{~s}$ and light cured for $20 \mathrm{~s}$ (miniLED, Satelec, France).

The cavities were restored as follow:

Group 1: restored with a room temperature Filtek Z350 XT;

Group 2: restored with a preheated $\left(37^{\circ} \mathrm{C}\right)$ Filtek Z350 XT;

Group 3: restored with a preheated $\left(60^{\circ} \mathrm{C}\right)$ Filtek Z350 XT;

Group 4: restored with a room temperature GC Kalore;

Group 5: restored with a preheated $\left(37^{\circ} \mathrm{C}\right)$ GC Kalore;

Group 6: restored with a preheated $\left(60^{\circ} \mathrm{C}\right)$ GC Kalore;

Group 7: restored with a room temperature Gradia direct $\mathrm{X}$;

Group 8: restored with a preheated $\left(37^{\circ} \mathrm{C}\right)$ Gradia direct $\mathrm{X}$;

Group 9: restored with a preheated $\left(60^{\circ} \mathrm{C}\right)$ Gradia di- rect $\mathrm{X}$.

All restorations were done two increments with the first against the gingival wall, and light-cured for $20 \mathrm{~s}$. Excess materials are removed with a No.170 bur, followed by finishing and polishing with the Softlex disk system (3M Dental Products Division, St. Paul, MN, USA). The restored teeth are stored in deionized water at $37^{\circ} \mathrm{C}$ for 1 day before further treatment.

All samples are thermocycled for 1000 cycles between 5 and $55^{\circ} \mathrm{C}$ with a dwell time of $1 \mathrm{~min}$, before immersion in dye. The apices of the teeth are sealed with blue wax and coated with a nail polish $1 \mathrm{~mm}$ short of the restoration margins in order to reduce other leakage elsewhere that could lead to false positive results. The teeth were immersed in $0.5 \%$ toluidine-blue solution for 24 hour at room temperature. The superficial dye is removed with a pumice slurry and rubber cup after removal of the specimens from the dye solution. Teeth are then mounted in a cold-cure epoxy resin $\left(\right.$ Leco $^{\circledR}$, Leco Corporation, MI, USA) to facilitate handling during sectioning.

\subsubsection{Microleakage Test}

To measure the extent of microleakage, the teeth were sectioned longitudinally through the restorations in a bucco-lingual direction with a low speed diamond saw (IsoMet ${ }^{\mathrm{TM}}$, Buehler Ltd., Lake Bluff, IL, USA), providing 3 sections per restoration. The sectioned teeth were evaluated with a stereomicroscope (Leica MZ8, Leica Microscopy System Ltd., Heerbrugg, Switzerland) at 20 $\times$ magnification. The degree of microleakage determined through dye penetration was scored according to standardized criteria (0 to 4; Table 2, Figure 2). Double blinded evaluators measured the slices and then the Kappa test was performed. Differences in the frequency distribution of scores between groups were assessed using the Kruskal-Wallis test and assessments within the groups were assessed using the Mann-Whitney U test. The results of testing were analyzed with statistical software $\left(\right.$ IBM $^{\circledR}$ SPSS $^{\circledR}$ Statistics Base 21, IBM, USA). Significance is considered at the 0.05 level.

\section{Results}

Average polymerization contraction stress of composites at room temperature and when preheated to $37^{\circ} \mathrm{C}$ and $60^{\circ} \mathrm{C}$ are shown in Table 3 and Figure 3. Figure 4 shows trend lines of the polymerization contraction force during 0 - 60 second. Results indicate that preheating composites to $37^{\circ} \mathrm{C}$ and $60^{\circ} \mathrm{C}$ significantly increased polymerization contraction stress and the developmental rate of polymerization contraction force $(p<0.05)$. Statistically greater amount of leakage was found at the cervical margins compared to the occlusal margins $(p<0.05)$ for the group restored with composites at room temperature and the group restored with composites at $37^{\circ} \mathrm{C}$. No 
Table 2. Microleakage scoring criteria.

\begin{tabular}{lc}
\hline $\mathbf{0}$ & No dye penetration \\
\hline $\mathbf{1}$ & Dye penetration up to one-half of the cavity wall \\
$\mathbf{2}$ & Dye penetration up to total cavity wall \\
$\mathbf{3}$ & Dye penetration up to one-half of the axial wall \\
$\mathbf{4}$ & Dye penetration more than one-half of the axial wall \\
\hline
\end{tabular}

Table 3. Average polymerization contraction stress of composites at room temperature and when preheated to $37^{\circ} \mathrm{C}$ and $60^{\circ} \mathrm{C}$.

\begin{tabular}{cccc}
\hline Materials & Room Temp & $\mathbf{3 7}^{\circ} \mathbf{C}$ & $\mathbf{6 0}^{\circ} \mathbf{C}$ \\
\hline GC Kalore & $4.18 \pm 0.02$ & $8.10 \pm 0.07$ & $9.85 \pm 0.04$ \\
Gradia Direct X & $5.61 \pm 0.02$ & $8.62 \pm 0.03$ & $10.72 \pm 0.05$ \\
Filtek Supreme XT & $11.83 \pm 0.01$ & $14.21 \pm 0.05$ & $16.39 \pm 0.05$ \\
\hline
\end{tabular}

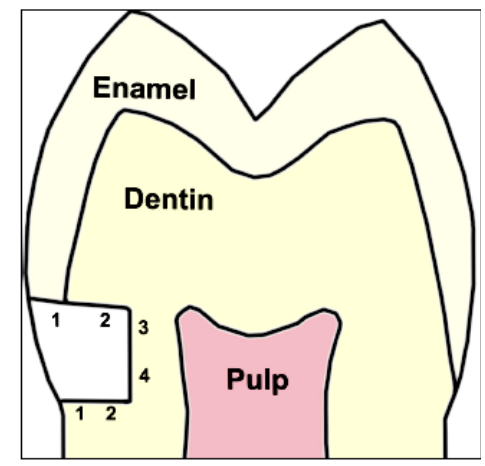

Figure 2. Diagram of Class V cavity and microleakage scoring.

statistical significant differences were observed among materials and temperatures at the occlusal margin. In contrast, for all materials tested, the $60^{\circ} \mathrm{C}$ preheated samples showed statistically lower microleakage at the cervical margin. In fact, there was no microleakage observed at the cervical margin for the group restored with composite preheated to $60^{\circ} \mathrm{C}$.

The polymerization contraction stress results were analyzed using General Linear Model, Multivariated Analysis of Variance (MANOVA), Tukey's and Scheffe's Post Hoc test. Highly significant differences were found both between materials and between temperatures $(p<$ 0.01).

The frequency distribution of different degrees of microleakage in the groups is shown in Table 4. There were significant differences between the microleakage scores for the enamel and dentin $(p<0.05)$. Less microleakage was observed at the occlusal margins than at the cervical margins. Only 2 restorations showed microleakage at the occlusal margins. There were no significant differences between materials and temperatures at the occlusal margins $(p>0.05)$. However, at the cervical margins, there

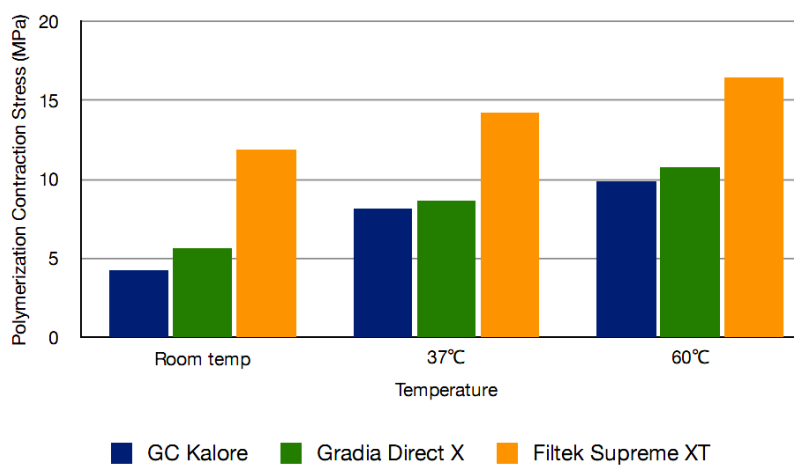

Figure 3. Polymerization contraction stress (MPa) of composites at different temperatures.

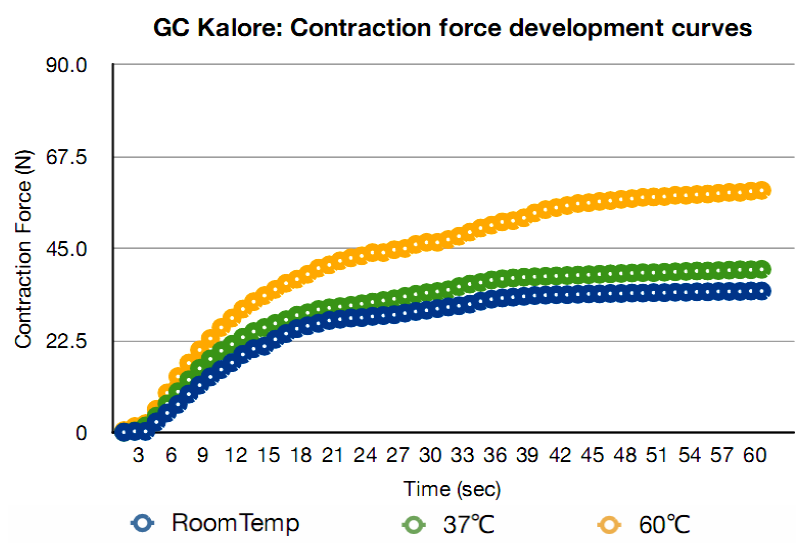

Filtek Supreme XT: Contraction force development curves

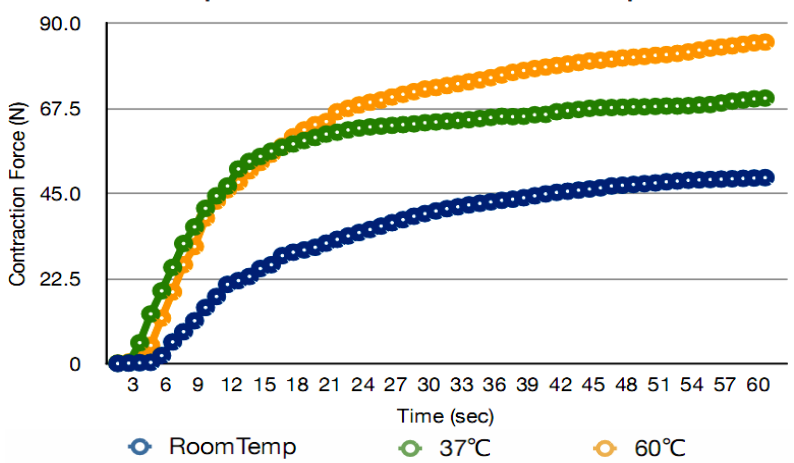

Gradia Direct X: Contraction force development curves

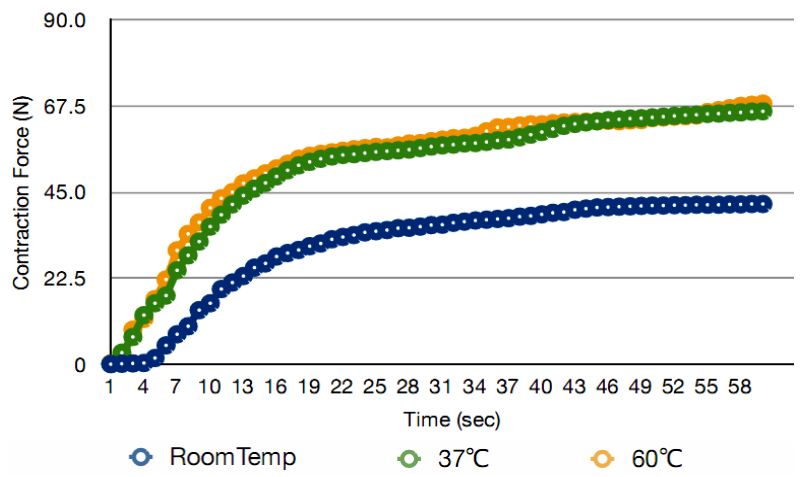

Figure 4. Polymerization contraction force during 0 - 60 second. 
Table 4. Frequency distribution of microleakage for each experimental group.

\begin{tabular}{|c|c|c|c|c|c|c|c|c|c|c|}
\hline \multirow{2}{*}{ Group } & \multicolumn{5}{|c|}{ Occlusal } & \multicolumn{5}{|c|}{ Gingival } \\
\hline & 0 & 1 & 2 & 3 & 4 & 0 & 1 & 2 & 3 & 4 \\
\hline Group 1: Filtek Supreme (control) & 7 & 1 & 0 & 0 & 0 & 4 & 3 & 0 & 1 & 0 \\
\hline Group 2: Filtek Supreme $\left(37^{\circ} \mathrm{C}\right)$ & 8 & 0 & 0 & 0 & 0 & 5 & 3 & 0 & 0 & 0 \\
\hline Group 3: Filtek Supreme $\left(60^{\circ} \mathrm{C}\right)$ & 8 & 0 & 0 & 0 & 0 & 8 & 0 & 0 & 0 & 0 \\
\hline Group 4: GC Kalore (control) & 8 & 0 & 0 & 0 & 0 & 5 & 2 & 0 & 1 & 0 \\
\hline Group 2: GC Kalore $\left(37^{\circ} \mathrm{C}\right)$ & 8 & 0 & 0 & 0 & 0 & 6 & 2 & 0 & 0 & 0 \\
\hline Group 3: GC Kalore $\left(60^{\circ} \mathrm{C}\right)$ & 8 & 0 & 0 & 0 & 0 & 8 & 0 & 0 & 0 & 0 \\
\hline Group 5: Gradia Direct X (control) & 7 & 1 & 0 & 0 & 0 & 5 & 3 & 0 & 0 & 0 \\
\hline Group 6: Gradia Direct X $\left(37^{\circ} \mathrm{C}\right)$ & 8 & 0 & 0 & 0 & 0 & 6 & 1 & 0 & 0 & 1 \\
\hline Group 7: Gradia Direct X $\left(60^{\circ} \mathrm{C}\right)$ & 8 & 0 & 0 & 0 & 0 & 8 & 0 & 0 & 0 & 0 \\
\hline
\end{tabular}

were significant differences among the preheated groups $(p<0.05)$. Preheat composites to $60^{\circ} \mathrm{C}$ significantly reduced the degree of cervical leakage in all materials tested. In fact, no microleakage was observed at the cervical margin in this group.

Figure 5 show representative stereomicroscopic images of the samples with and without cervical microleakage.

\section{Discussion}

The objective of this experimental study was to evaluate the effect of preheating temperatures on polymerization contraction stress of composites and to investigate the extent of in vitro marginal microleakage of Class $\mathrm{V}$ resin composite restoration restored with preheated composites as compare to the cavity restored with room temperature composites. The extent of leakage after thermal cycling is relevant to clinical practice since microleakage of saliva, oral fluids and bacteria at the tooth-restoration interface has been linked causally to a range of problems, including marginal staining, postoperative sensitivity, and secondary caries. The integrity and durability of the marginal seal is an important factor in the longevity of adhesive dental restorative materials, particularly for composite resins. The absence of a seal at restoration margins permits the entry of oral bacteria and fluids, which can result in postoperative sensitivity, adverse pulpal responses and recurrent caries [7]. In the present study, standardized methods were used to minimize confounding factors. The dye penetration test is the most widely used laboratory method for assessing leakage, and for the purposes of this study a simple grading system was used [8]. The apical extent of the test cavities was intentionally placed into the root surface because leakage at this site is known to be a clinical concern when Class II and Class V cavities are restored with composite resin materials.

The results show that preheating composites signifi-

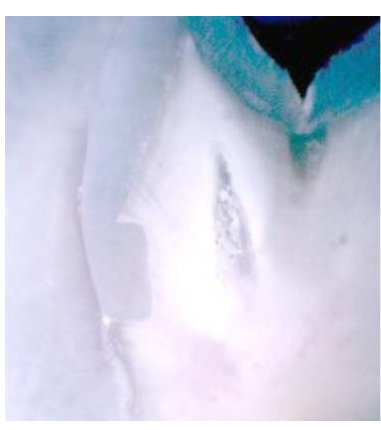

(a)

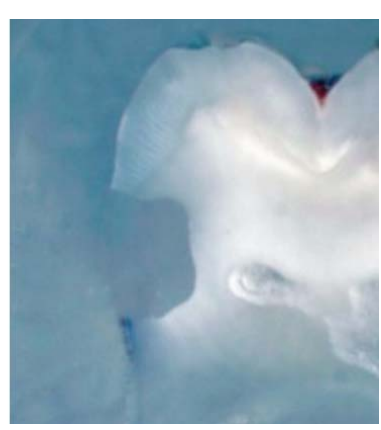

(b)
Figure 5. Representative stereo-microscopic images of the cavity with microleakage (a) and without cervical microleakage (b).

cantly increased polymerization contraction stress of composites and for all materials tested, preheating to $60^{\circ} \mathrm{C}$ resulted in significant reduction of microleakage at the cervical margin. This is agreed with Fróes-Salgado et $a l$. who evaluated the effect of pre-heating on marginal adaptation, monomer conversion, flexural strength, microhardness, and polymer cross-linking of a resin composite under a non-isothermal condition. They found that under non-isothermal conditions (similar to a clinical situation) preheating composite to $68^{\circ} \mathrm{C}$ did not improve the degree of conversion, flexural strength or polymer crosslinking, but yielded enhanced marginal adaptation [9]. Wagner et al. also found that preheating composites can improve adaptation of resin composites to tooth structure and significantly reduced microleakage, although delay of light curing after placement appears to be counterproductive and diminishes the positive effects from the preheating treatment [10]. They also concluded that flowable liner was less effective than preheating the composite in reducing microleakage. Interestingly, the previous expectation that composite preheating could worsen the marginal adaptation of composites to the cavity walls due to the increased conversion rates $[1,2]$ and consequently increased polymerization shrinkage [11,12] 
was not confirmed by the results of the present investigation. The results shows that preheating composite to high temperatures lead to an increase in polymerization contraction stress but less microleakage at the cervical margin. This is in contrast with several studies that have shown a direct relationship between contraction stress and marginal leakage in resin composite restorations [13-15]. This was also expected because resin composites exhibit a six to eight times greater thermal expansion than the surrounding tooth structures $[9,16]$, polymerization shrinkage along with thermal contraction might create high interfacial stresses in preheated composites upon thermal equilibrium, with detrimental effects on marginal adaptation, integrity and seal [13]. Further investigation is therefore needed regarding advantages and disadvantages of dental composite preheating before we can make a conclusion if this method is appropriate in dental practice.

\section{Conclusion}

The present finding suggests that in the challenging situation of the cervical restoration which extends onto the root surface, preheating composites to $60^{\circ} \mathrm{C}$ significantly reduced microleakage at the tooth-restoration interfaces. Preheating however results in non-desirable increase of polymerization contraction stress. More investigation should be done regarding the consequence of the increased stress at the tooth restoration interfaces to the strength of the restored tooth.

\section{REFERENCES}

[1] M. Trujillo, S. M. Newman and J. W. Stansbury, "Use of Near-IR to Monitor the Influence of External Heating on Dental Composite Photopolymerization," Dental Materials, Vol. 20, No. 8, 2004, pp. 766-777. http://dx.doi.org/10.1016/j.dental.2004.02.003

[2] M. Daronch, F. A. Rueggeberg and M. F. De Goes, "Monomer Conversion of Pre-Heated Composite,” Journal of Dental Research, Vol. 84, No. 7, 2005, pp. 663-667. http://dx.doi.org/10.1177/154405910508400716

[3] M. Daronch, F. A. Rueggeberg, L. Moss and M. F. de Goes, "Clinically Relevant Issues Related to Preheating Composites," Journal of Esthetic and Restorative Dentistry, Vol. 18, No. 6, 2006, pp. 340-350. http://dx.doi.org/10.1111/j.1708-8240.2006.00046.x

[4] J. L. Ferracane and E. H. Greener, "The Effect of Resin Formulation on the Degree of Conversion and Mechanical Properties of Dental Restorative Resins," Journal of Biomedical Materials Research, Vol. 20, No. 1, 1986, pp. 121-131. http://dx.doi.org/10.1002/jbm.820200111

[5] A. A. El Hejazi and D. C. Watts, "Creep and Viscoelastic Recovery of Cured and Secondary-Cured Composites and Resin-Modified Glass-Ionomers,” Dental Materials, Vol.
15, No. 2, 1999, pp. 138-143. http://dx.doi.org/10.1016/S0109-5641(99)00023-8

[6] R. Walter, E. J. Swift, H. Sheikh and J. L. Ferracane, "Effect of Temperature on Composite Resin Shrinkage," Quintessence International, Vol. 40, No. 10, 2009, pp. 843-847.

[7] V. Armengol, A. Jean, B. Enkel, M. Assoumou and H. Hamel, "Microleakage of Class V Composite Restorations Following Er:YAG and Nd:YAG Laser Irradiation Compared to Acid-Etch: An in Vitro Study," Lasers in Medical Science, Vol. 17, No. 2, 2002, pp. 93-100. http://dx.doi.org/10.1007/s101030200016

[8] N. Gutknecht, C. Apel, C. Schafer and F. Lampert, "Microleakage of Composite Filling in Er, Cr:YSGG LaserPrepared Class II Cavities," Lasers in Surgery and Medicine, Vol. 28, No. 4, 2001, pp. 371-374. http://dx.doi.org/10.1002/lsm.1064

[9] N. Fróes-Salgado, L. Silva, Y. Kawano, C. Francci, A. Reis and A. Loguercio, "Composite Preheating: Effects on Marginal Adaptation, Degree of Conversion and Mechanical Properties,” Dental Materials, Vol. 26, No. 9, 2010, pp. 908-914.

http://dx.doi.org/10.1016/j.dental.2010.03.023

[10] W. Wagner, M. Aksu, A. Neme, J. Linger, F. Pink and S. Walker, "Effect of Pre-Heating Resin Composite on Restoration Microleakage,” Operative Dentistry, Vol. 33, No. 1, 2008, pp. 72-78. http://dx.doi.org/10.2341/07-41

[11] U. Lohbauer, S. Zinelis, C. Rahiotis, A. Petschelt and G. Eliades, "The Effect of Resin Composite Pre-Heating on Monomer Conversion and Polymerization Shrinkage," Dental Materials, Vol. 25, No. 4, 2009, pp. 514-519. http://dx.doi.org/10.1016/j.dental.2008.10.006

[12] N. Silikas, G. Eliades and D. C. Watts, "Light Intensity Effects on Resin-Composite Degree of Conversion and Shrinkage Strain,” Dental Materials, Vol. 16, No. 4, 2000, pp. 292-296. http://dx.doi.org/10.1016/S0109-5641(00)00020-8

[13] D. C. Watts, M. Issa, A. Ibrahim, K. Wakiaga, M. AlSamadini and N. Silikas, "Edge Strength of Resin-Composite Margins,” Dental Materials, Vol. 24, No. 1, 2008, pp. 129-133. http://dx.doi.org/10.1016/j.dental.2007.04.006

[14] J. L. Ferracane and J. C. Mitchem, "Relationship between Composite Contraction Stress and Leakage in Class V Cavities," The American Journal of Dentistry, Vol. 16, No. 4, 2003, pp. 239-243.

[15] F. C. Calheiros, F. T. Sadek, R. R. Braga and P. E. Capel Cardoso, "Polymerization Contraction Stress of LowShrinkage Composites and Its Correlation with Microleakage in Class V Restorations," Journal of Dentistry, Vol. 32, No. 5, 2004, pp. 407-412. http://dx.doi.org/10.1016/j.jdent.2004.01.014

[16] S. K. Sidhu, T. E. Carrick and J. F. McCabe, "Temperature Mediated Coefficient of Dimensional Change of Dental Tooth-Colored Restorative Materials,” Dental Materials, Vol. 20, No. 5, 2004, pp. 435-440. http://dx.doi.org/10.1016/j.dental.2003.02.001 